units, $b$ becomes $\log \varphi_{B}$, the logarithm of the fluidity at the boiling point under $760 \mathrm{~mm}$. of mercury pressure.

For substances examined having $a$ approximately $0 \cdot 24$, it has been found that the function $M \log \Phi_{B}$, where $M$ is the molecular weight, can be evaluated from a list of atomic and structural constants, and the fluidity of a given non-associated liquid at its boiling point be calculated with an average error of 3 per cent.

Work on these lines is now in progress together with an examination of the above relationships as applied to liquid solutions. Full details will be published as soon as possible.

Department of Chemical Engineering,

L. H. Thomas.

School of Mines and Technology,

Treforest.

Feb. 5 .

Phì. Mag., 23, 458 (1912).

\section{Effect of Electrically Induced Convulsions on the Sugar Tolerance of Psychotic Patients}

In this Hospital, investigations are being made on the sugar tolerance curves of a number of psychotic patients. Abnormal curves in such patients have been found by workers in the past ${ }^{1,2}$.

As progress is comparatively rapid during electric convulsion therapy, it was felt that possible changes in these curves during treatment might be present and this was in fact found to be so. Patients suffering from depressive and manic depressive insanity show the greatest abnormality in their sugar tolerance and also the greatest change in this during treatment. The typical curve before treatment is shown in the accompanying graph. The fasting level is normal or slightly raised, there is a rapid rise to heights well above physiological limits followed by a sharp descent, but not reaching the original level in two hours.

After two to six convulsions, although the mental condition improves, the curves show increasing

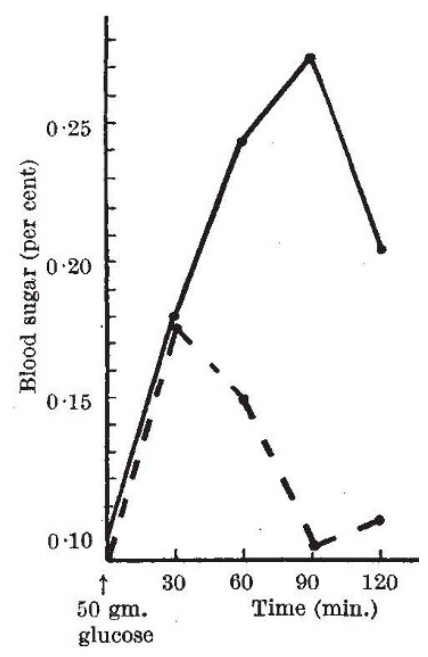

SUgar TOLERANCE CURVE

Full line, patients ; broken line, average normal. abnormality. Thus, in most cases the fasting level is raised and the maximum reached in half or one hour is in the region of $0.4 \mathrm{gm}$. per cent. Gradually, after the mental condition has been normal for many weeks, the curves become normal too.

In all cases of depression the first effects of electric convulsion therapy on the sugar-tolerance curve is to raise both the fasting level and the maximum.

This profound physiological disturbance described above is of great significance since it shows, at least for some mental disorders, a relationship between metabolism and the so-called functional disorders.

This investigation is being continued.

County Mental Hospital,

A. GLYnN.

\section{Lancaster.}

Jan. 23.

2 Drury and Farren Ridge, J. Mental Sci. (1925).

2 Mann, S. A., J. Mental Sci. (1925).

\section{Estrogenic Substances showing Anti- tumour Action}

Contrary to the general impression (due to publications attributing carcinogenic properties to ostrogens when administered to both sexes of different animals; also the œstrogenic activity, although notably weak, of many carcinogens), I have during my researches ${ }^{1,2}$ on oestrogens come to believe that these compounds are not carcinogenic, and that they will most probably show at least some curative influence in the case of tumour diseases. I submitted a detailed report on "Estrogens as Anti-tumour Compounds" to the Ministry of Public Health in Egypt on May 30, 1944. An account of the influence of synthetic œstrogens upon advanced malignant disease was recently published ${ }^{3}$.

Owing to the remarkably prolonged action of $\alpha \alpha$ - di - ( $p$ - ethoxyphenyl) - $\beta$ - phenylbromoethylene $e^{4,5}$ when given orally, and its remarkably low toxicity, if any ${ }^{6}$, it was proposed to use this substance in the treatment of ovarian tumours and cancer of breast. The following describes its influence in two cases of cancer :

Case 1. A patient fifty-seven years old was operated on for breast cancer, the right mammary gland being removed. Seventeen months later recurrence with metastases in the liver was noted. Within the next eight weeks the patient became much worse, became dumb, the fæces became colourless apparently indicating biliary obstruction, and odema developed in both legs and in the right arm. On July 3, 1943, a 100 -mgm. cachet of $\alpha \alpha$-di-( $p$-ethoxyphenyl $)$ - $\beta$-phenylbromoethylene was given to the patient, and on the following three days, a 250-mgm. cachet was given daily. The oedema completely disappeared within five days from the beginning of the treatment, the fæces resumed the normal colour and the patient spoke once. The patient, however, died on July 10, 1943.

Case 2. A patient aged forty-five suffering from sarcoma ovarialis of a comparatively large size had the abdomen opened in the King's Hospital, Cairo, on July 31,1943 , and the tumour being inoperable, was left untouched. The tumour continued to increase in size, filling the abdomen and pressing against the different abdominal organs. Treatment with $\alpha \alpha$-di-( $p$-ethoxyphenyl)- $\beta$-phenylbromoethylene began on August 23, 1944, the œestrogen being administered 